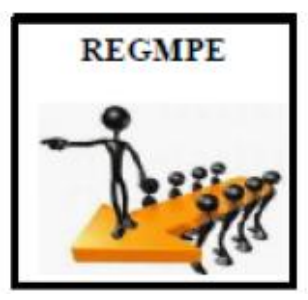

Revista de Empreendedorismo e Gestão de

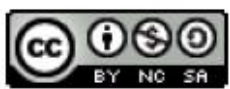

Micro e Pequenas Empresas

\title{
O PLANO DE MARKETING COMO FERRAMENTA PARA ALAVANCAR A PEQUENA EMPRESA: ESTUDO DE CASO
}

\section{THE MARKETING PLAN AS A TOOL TO LEVERAGE THE SMALL BUSINESS: A CASE STUDY}

\section{Resumo}

Henri Cristian Messa Corassa ${ }^{1}$

A recente crise econômica gerou consideráveis mudanças na realidade socioeconômica do cidadão brasileiro. Uma delas foi o aumento significativo de pessoas que buscaram através do empreendedorismo uma solução ao desemprego. Contudo, a criação e a gestão de uma pequena empresa não é uma atividade simples, requer planejamento e dedicação - é num elemento do primeiro ponto que se debruça este trabalho: o plano de marketing enquanto ferramenta de planejamento. Baseado nesta ferramenta, a presente pesquisa buscou compreender a importância do plano de marketing na alavancagem dos pequenos empreendimentos utilizando como contexto a análise de um pequeno negócio real, situado em Porto Alegre e inserido no ramo de panificação e de alimentação saudável. Organizado como um estudo de caso para aprendizagem, averiguou-se as principais estruturas de um plano de marketing, quais eram praticadas pelo empreendimento e as estratégias de marketing para o seu crescimento.

Palavras-chave: empreendedorismo; padaria artesanal; plano de marketing; pequenos empreendimentos.

\begin{abstract}
The recent economic crisis has generated considerable changes in the socioeconomic reality of Brazilian citizens. One of them was the significant increase in the number of people who sought through entrepreneurship a solution to unemployment. However, the creation and management of a small company isn't a simple activity, it requires planning and dedication - it's an element of the first point that this work focuses on: the marketing plan as a planning tool. Based on this tool, the present research sought to understand the importance of the marketing plan in leveraging small businesses using as context the analysis of a real small business, located in Porto Alegre and inserted in the bakery and healthy eating branch. Organized as a case study for learning, investigated the main structures of a marketing plan, which were practiced by the enterprise and the marketing strategies for its growth.
\end{abstract}

Keywords: entrepreneurship; artisanal bakery; marketing plan; small business

\footnotetext{
1 Bacharel em Ciências Jurídicas e Sociais pela UFRGS. Especialista em Compliance pela PUCRS. Discente do curso de especialização em Gestão Empresarial do IFRS. E-mail: hcorassa@gmail.com. http://lattes.cnpq.br/7918513007742051. https://orcid.org/0000-0002-8404-8065.

Corassa, H.C.M.; O Plano De Marketing Como Ferramenta Para Alavancar A Pequena Empresa: Estudo De Caso. Revista de Empreendedorismo e Gestão de Micro e Pequenas Empresas V.5, No3, p.1-22, Set/Dez. 2020. Artigo recebido em 10/07/2020. Última versão recebida em 02/010/2020. Aprovado em 15/11/2020.
} 


\section{O Plano De Marketing Como Ferramenta Para Alavancar A Pequena Empresa: Estudo De Caso.}

\section{Introdução}

O Brasil enfrenta atualmente uma crise econômica que para muitos especialistas teve início em 2014 e que não se sabe quando terá fim. O momento de incerteza e insegurança pelo qual a sociedade passa, conduz a um mercado de trabalho saturado de profissionais devido à diminuição dos postos de trabalho nas grandes empresas. Em razão disso, observa-se um movimento que caminha em direção ao empreendedorismo por meio dos microempreendedores individuais e das micros e pequenas empresas. Dados do Serviço Brasileiro de Apoio às Micro e Pequenas Empresas (SEBRAE) apontam que as micros e pequenas empresas (MPEs) compõem 98\% do mercado nacional. Estima-se que elas estejam na ordem de mais de 6,4 milhões de empresas em todo o país e que em conjunto formem uma grande força econômica correspondente a 27\% do PIB (SEBRAE, 2019). A geração de um empreendimento local representa um incremento para a economia de sua região. Além do desenvolvimento do negócio e do empresário, esse tipo de iniciativa gera empregos que impulsionam o desenvolvimento econômico-social local. Partindo de dados do SEBRAE, em 2018 as MPEs representaram 52\% dos empregos com carteira assinada do setor privado no Brasil. (SEBRAE, 2019)

Frente a tal contexto, evidenciam-se os negócios desenvolvidos no ramo de alimentação. Mercado que tem ganho maior abrangência e desenvolvido novos nichos, principalmente ao falar-se em alimentação saudável. Segundo o SEBRAE, o Brasil é o quarto maior mercado do mundo quando se fala em alimentação saudável. A compartimentação do mercado consumidor tem ganhado força com o desenvolvimento tecnológico e o surgimento de novas dietas alimentares, sejam elas com o objetivo estético, de adequação a novos estilos de vida ou por razões médicas, como as restrições alimentares. De acordo com a Federação Nacional das Associações de Celíacos do Brasil (FENACELBRA), estima-se que 2 milhões de brasileiros tenham alergia ao glúten, proteína amplamente presente em alimentos processados. 


\section{O Plano De Marketing Como Ferramenta Para Alavancar A Pequena Empresa: Estudo De Caso.}

Ainda, observa-se que tais negócios, devido a sua natureza de nicho ${ }^{2}$, são notadamente pautados pela hiperconectividade. Neste cenário, o empreendedor mostra-se como alguém que deve perceber as demandas emergentes e saber posicionar-se oportunamente no mercado. Surge assim, como algo essencial e evidente, por parte do dono do empresário, a importância de que o seu negócio possua um robusto plano de marketing.

Partindo do panorama exposto e para guiar e entender essa necessidade - de todo e qualquer empreendimento ter um bom plano de marketing - o presente estudo se justifica como algo necessário. Desta forma, este trabalho tem como objetivo principal compreender a importância do plano de marketing ao micro e pequeno empresário. Como objetivos secundários, irá detectar os elementos básicos de um plano de marketing para alavancar um pequeno negócio local e, também, identificará a análise de mercado e a estratégia de marketing adotada pela empresa em estudo, assim, apresentando suas oportunidades de crescimento.

A partir de uma abordagem de estudo de caso para a aprendizagem de futuros empreendedores, observou-se a padaria Borks - pães artesanais, situada em Porto Alegre. Pois, tradicionalmente conhecidas na economia brasileira como negócios locais, as padarias artesanais estão presentes em quase todos os bairros de qualquer cidade e representam um bom tipo de empreendimento inicial.

\section{Fundamentação teórica}

\subsection{Marketing}

Ponto estrutural deste trabalho, Stringhini (2007) define o marketing como o conjunto de atividades cujo intuito é levar bens e serviços do produtor ao consumidor. O autor esclarece que sua área de atuação é mais ou menos ampla pois muito dependerá do enfoque que lhe der a empresa, isto é, a abordagem dele varia de acordo com a natureza do empreendimento. Ainda, complementa que o marketing é uma técnica de administração, na qual a empresa deve estabelecer seus os objetivos organizacionais de acordo com as necessidades, desejos e satisfação do mercado-alvo, atuando de maneira mais efetiva e eficiente do que os concorrentes.

\footnotetext{
${ }^{2}$ De acordo com Chris Anderson (2006), vivemos no mercado de variedades da internet onde ocorre demasiada oferta de bens de nicho (singulares) em pequenas quantidades, se contrapondo ao fluxo da economia de massa tradicional que oferta pouca variedade de produtos que vendem mais (hits).
} 


\section{O Plano De Marketing Como Ferramenta Para Alavancar A Pequena Empresa: Estudo}

De Caso.

Por sua vez, Pinheiro e Gullo (2013) conceituam o marketing como um processo de trocas entre pessoas e empresas, no qual emprega técnicas específicas para delinear estratégias que atinjam os propósitos de ambas - o seu emprego envolve características humanas, sociais e administrativas. Para Cobra (2009, p. 06), "a troca é o conceito central do marketing, ou seja, uma pessoa oferece dinheiro para ter a posse de um produto ou adquirir um serviço".

Como percebe-se, o marketing está intimamente conectado à relação entre consumidor e empresa e todo o ambiente que circunda essa. Trata-se de um importante pilar dentro de qualquer negócio. Na ótica de Kotler (2003, p. 11), a "gestão de marketing é a arte e a ciência de escolher os mercados-alvo e de conquistar, reter e cultivar clientes, por meio da criação, comunicação e fornecimento de valor superior para os clientes”. Dornelas (2016, p. 154) retrata o objetivo do marketing ao explicar que ele "deve dar conta de responder qual participação de mercado a empresa quer atingir, quanto quer vender, quanto quer lucrar, em quais segmentos e regiões, com que penetração de mercado, para quais consumidores e em qual prazo".

Almejando apresentar o conceito de marketing de uma forma mais organizada, Kotler (2001) o divide em duas perspectivas, a social e a gerencial. Para ele, a definição de marketing sob a visão social consiste em um processo pelo qual pessoas e grupos de pessoas conseguem aquilo que necessitam e o que anseiam com a criação, oferta e negociação de produtos e serviços de valor com outros membros da sociedade (KOTLER, 2001). Enquanto isso, inserido na visão gerencial, o marketing identifica-se como o "processo de planejar e executar a concepção, a determinação de preço (princing), a promoção e a distribuição de ideias, bens e serviços para criar negociações que satisfaçam metas organizacionais e individuais” (KOTLER, 2001, p.30).

De maneira a esclarecer a evolução do marketing ao longo dos anos, Kotler (2017) traz que no mundo altamente tecnológico em que estamos, as pessoas anseiam por um envolvimento profundo com as marcas. "O tradicional marketing centrado no produto (marketing 1.0) passou a ser voltado para o consumidor (marketing 2.0), e após centrado no ser humano (marketing 3.0)", hoje estaria na fase de engajamento do cliente com a marca. Para o autor esta fase seria o que ele define como marketing 4.0.

\subsection{Plano de marketing}




\section{O Plano De Marketing Como Ferramenta Para Alavancar A Pequena Empresa: Estudo De Caso.}

O plano de marketing traduz, por meio de ações, a estratégia de marketing de uma empresa. Como explica Polizei em entrevista à Universidade Metodista de São Paulo (2010), o plano de marketing corresponde entre $70 \%$ e $90 \%$ do plano de negócios - uma vez que aquele está contido neste. A diferença entre eles é a de que o plano de negócios acrescenta detalhes de operações, logística entre outras implicações internas ao negócio, enquanto o plano de marketing foca mais amplamente no ambiente externo, ou melhor, no mercado.

Assim, para o sucesso do empreendimento, cabe ao plano de marketing identificar como as relações humanas estão estabelecidas e como elas impactam diretamente no seu segmento de mercado. Por exemplo, dois fatores que necessitam ser analisados são a influência da internet como alicerce da organização atual de nossa sociedade (CASTELLS, 2003), ferramenta altamente presente na vida de muitos indivíduos, e o aumento da demanda dos consumidores por produtos cada vez mais personalizados, específicos. Ambos têm impacto direto sobre o desempenho de qualquer empreendimento, sendo ele de pequeno ou de grande porte.

Segundo Kotler e Keller (2012, p. 55) "um plano de marketing é um documento escrito que resume o que o profissional de marketing sabe sobre o mercado e que indica como a empresa planeja alcançar seus objetivos”. De modo complementar, o estudioso Gomes (2013, p.9) pontua que o plano, regularmente utilizado e atualizado, "permite analisar o mercado, adaptando-se as suas constantes mudanças e identificando tendências. Por meio dele você pode definir resultados a serem alcançados e formular ações para atingir competitividade". Observada a importância do plano de marketing dentro do universo empresarial, agora compete distinguir a existência de duas estruturas básicas, cerne do plano de marketing, e que necessitam ser delineadas: a análise de mercado e a estratégia de marketing.

\subsubsection{Análise de mercado}

Talvez a análise de mercado seja uma das fases mais estratégicas para um plano de marketing. Ela irá identificar as situações do ambiente que irão impactar no negócio. Como etapa inicial de um plano de marketing, nela cabe realizar o levantamento do maior número possível de dados sobre os fatores que influenciam, positivamente ou negativamente, a empresa - sejam eles diretos ou indiretos. Após a identificação e análise destes dados é que o empresário poderá formular estratégias e assumir riscos inerentes a sua atividade. Por estas razões, pode- 


\section{O Plano De Marketing Como Ferramenta Para Alavancar A Pequena Empresa: Estudo De Caso.}

se afirmar que é mediante a análise estratégica do mercado que o empresário irá estabelecer medidas para evitar o insucesso do seu negócio.

Deve-se ter em mente que cada empreendimento tem a sua análise de mercado. Por mais que existam fatores comuns em um determinado ramo empresarial, fatores locais e temporais tornam ela personalíssima, individual. Como Dolabela (1999) explica, a análise de mercado deve observar as oportunidades e ameaças nos diversos aspectos que influenciam o negócio: demográficos, econômicos, legais, políticos, tecnológicos e culturais. Também deve avaliar a suscetibilidade do negócio a intervenções governamentais, novas leis e regulamentações, assim como, analisar os seus consumidores, mudanças na pirâmide etária, cultura e a influência que isso tem sobre as vendas - fatores trabalhados pela doutrina como ambiente externo, uma vez que o empresário não possui controle sobre elas. Outra etapa da análise de mercado é o exame dos fatores internos da empresa, também conhecidos por forças e fraquezas do negócio. Neles estão inseridos pontos como a disponibilidade e a capacidade de alocação de recursos - humanos e financeiros, a cultura organizacional existente e a almejada.

Em resumo, quanto mais detalhada for a análise dos fatores, maior será a chance de sucesso. Posto isto, é imprescindível identificar os meios hábeis para a elaboração dessa análise. A matrizes de análise são ferramentas capazes de oferecer dados ao empresário e subsidiarem a formulação de uma estratégia de marketing sólida.

\subsubsection{Matriz de análise}

Autores compreendem que "em um mercado altamente competitivo, além das pesquisas tradicionais de mercado é preciso fazer análises, com metodologias que auxiliem na percepção e nas decisões de marketing" (SILVA et al., 2006, p.44). Nessa ótica, as matrizes de análise de mercado apresentam-se como eficazes ferramentas. Responsáveis por agregar qualidade e credibilidade ao plano de marketing, elas são mais ágeis de fazer, valorizam a análise, possibilitam o cruzamento de informações, e geralmente são capazes de traduzir uma matéria qualificativa em quantitativa, agilizando o entendimento de quem lê.

Atualmente conta-se com diversas matrizes difundidas no campo da gestão estratégica. Matrizes como a matriz BCG, o modelo das cinco forças de Porter, a matriz de avaliação de entrantes potenciais, a matriz de Ansoff e a matriz de política direcional (ou GE) são exemplos destas. Para o desenvolvimento deste estudo, optou-se pela SWOT, também nomeada como 
O Plano De Marketing Como Ferramenta Para Alavancar A Pequena Empresa: Estudo De Caso.

F.O.F.A. A matriz SWOT (Strengths, Weaknesses, Opportunities and Threats) é um demonstrativo rápido e eficaz dos principais aspectos positivos e negativos de uma empresa ou de seu produto, levando-se em consideração os cenários internos e externos que os permeia.

Como observa-se, quadrantes vinculados ao ambiente interno da empresa tem-se: $(a)$ pontos fortes, no qual deve-se listar as variáveis mais positivas da sua empresa em relação aos seu produto - neste quadrante podem ser analisadas as competências essenciais da empresa, a competência da marca, a capacidade de inovação, a disponibilidade para crescer, a participação no mercado a competência de vendas; e $(b)$ pontos fracos, que por sua vez representam as variáveis mais negativas da empresa em relação ao produto - neste quadrante podem ser analisadas a falta de domínio em competências essenciais, dificuldades financeiras para novos projetos, resistência interna a inovação, custos operacionais elevados, imagem deficiente do produto, gerência despreparada.

Já no ambiente externo, a matriz divide-se entre: $(a)$ oportunidades, quadrante destinado a listagem dos aspectos mais positivos em relação ao mercado, como a existência de chances de rápida penetração no mercado, a saída do maior concorrente do mercado, boas fontes de financiamento, o aumento significativo de vendas; e (b) ameaças, em contraposição, é o quadrante destinado aos aspectos mais negativo em relação ao mercado, como uma modificação negativa na lei tributária, aumento inesperado na taxa do dólar, a reação dos concorrentes ou entrada de novos, elevação da inflação com queda na taxa de consumo. Por sua simplicidade, essa matriz visa realizar uma rápida e prática análise do mercado. A sua constante atualização, com os devidos aperfeiçoamentos, capacita-a ser uma poderosa ferramenta de marketing. A partir das informações levantadas torna-se viável traçar objetivos e metas para o negócio e, assim, formular uma estratégia de marketing.

\subsubsection{Estratégia de marketing}

Percorrendo o caminho para a formulação do plano de marketing, alcança-se uma importante etapa: a definição da estratégia de marketing, isto é, de como a empresa atuará no mercado. Após a etapa de análise de mercado, embasada por uma análise estratégica, é possível atingir a etapa de formulação dos objetivos da empresa, assim como, de suas metas. Tendo tudo isso delineado, a empresa tem condições de estruturar a sua estratégia de marketing. Nesta 


\section{O Plano De Marketing Como Ferramenta Para Alavancar A Pequena Empresa: Estudo De Caso.}

etapa, é interessante esclarecer que objetivos e metas possuem conceitos distintos. Para Silva e outros (2006) os objetivos são uma descrição de um estado futuro que a empresa visa alcançar, definidos de forma específica e mensurável pela empresa. Em contrapartida, as metas devem ser compreendidas como pontos intermediários estabelecidos no caminho para atingir os objetivos. Eles devem ser suscetíveis de controle e acompanhamento e apresentar prazos definidos de alcance, demonstrando se a empresa está no caminho certo.

A estratégia de marketing, portanto, será o instrumento responsável por orientar as ações que a empresa desenvolverá a fim de atingir às metas e aos objetivos estabelecidos. Ela será a designadora dos meios e dos métodos para tanto, pois é de acordo com a estratégia de marketing que os recursos da empresa serão direcionados - seja para o desenvolvimento de novos produtos, relacionamento com o consumidor, melhoramento da qualidade ou reposicionamento da marca em novos mercados (SILVA et al., 2006, p.82). Nesse aspecto, Dornelas (2012) exemplifica bem a relação da estratégia de marketing com as demais estruturas da empresa (principalmente as relacionadas ao marketing). Ele explica que a estratégia de marketing e a projeção de vendas estão intimamente interligadas uma vez que ao adotar-se uma estratégia que altere alguma das estruturas de marketing, como o posicionamento do produto no mercado, a política de preços, a promoção e os canais de venda ou como chegará o produto ao cliente, ela impactará diretamente na projeção de vendas. Esta pode manter-se estável ou oscilar, positiva ou negativamente, em razão da estratégia adotada. Em suma, "ela consiste nas decisões necessárias para determinar a maneira pela qual os principais elementos de marketing serão combinados simultaneamente" (SEBRAE, 2013, p. 38).

\section{Apresentando o caso: plano de marketing de uma pequena padaria artesanal de Porto} Alegre

A partir do que foi exposto, trataremos dos procedimentos metodológicos escolhidos e, após, iniciaremos a análise do empreendimento a partir da teoria vista nos capítulos anteriores.

\subsection{Procedimento metodológico}

Este estudo é uma pesquisa exploratória, desenvolvida sob a modalidade de estudo de caso único, com abordagem metodológica de natureza qualitativa das informações coletadas. Tal opção tem o intuito de proporcionar "análises mais profundas em relação ao fenômeno que 


\section{O Plano De Marketing Como Ferramenta Para Alavancar A Pequena Empresa: Estudo De Caso.}

está sendo estudado" (BEUREN, 2010, p.32) e, por conseguinte, o aprofundamento na compreensão do objeto.

Em consonância a isso, adotou-se como estratégia o estudo de caso voltado à aprendizagem, isto é, a observação de um caso inserindo-se num processo de transformação de experiências do empreendedor em conhecimento, ou melhor, uma aprendizagem empreendedora (ZAMPIER e TAKAHASI, 2011 apud POLITIS, 2005). Como Yin (2001) destaca, ela tem por enfoque responder o "como" e o "porque" sobre um conjunto contemporâneo de acontecimentos inseridos na vida real e sobre o qual o pesquisador tem pouco ou nenhum controle, não se podendo manipular os comportamentos relevantes. O seu emprego objetivou não realizar uma intervenção direta no objeto de análise, mas conhecê-la, revelá-la por meio de uma observação pragmática (FONSECA, 2002) e, de igual modo, contribuir para a formação de conhecimento aplicável na aprendizagem empreendedora ${ }^{3}$ para micro e pequenas empresas (ZAMPIER e TAKAHASHI, 2011).

O objeto de estudo foi o empreendimento Borks - pães artesanais, estabelecido no município de Porto Alegre/ RS e os sujeitos da pesquisa são os dois sócios-empresários criadores. Os dados foram prioritariamente coletados por meio de análise do conteúdo presente na plataforma de vendas on-line e nas redes sociais, principais canais de comunicação e marketing utilizados pelo negócio. Após, foram realizadas entrevistas com os donos do empreendimento orientada por um roteiro de entrevista (GERHARDT e SILVEIRA, 2009), gravadas e posteriormente transcritas e também foi realizada a observação do local (loja física, local de produção e pontos de venda parceiros) e dos documentos fornecidos pelos sujeitos da pesquisa. A análise dos dados obtidos apreciou elementos subjetivos constantes nas diferentes fontes de evidências e utilizou como fundamento lógico de validação a triangulação destas (YIN, 2001). Com isso, objetivou-se agregar a solidez exigida pela metodologia do estudo de caso e pela técnica de pesquisa da análise de conteúdo (GERHARDT e SILVEIRA, 2009).

\subsection{Conhecendo o empreendimento - Borks: pães artesanais}

\footnotetext{
${ }^{3}$ Zampier e Takahashi $(2011$, p.) conceituam a aprendizagem empreendedora como: “[...] um processo contínuo que facilita o desenvolvimento de conhecimento necessário para começar novos empreendimentos e administrálo, sendo os conhecimentos advindos da experiência pessoal do empreendedor e utilizados para guiar a escolha de novas experiências (POLITIS, 2005).
} 


\section{O Plano De Marketing Como Ferramenta Para Alavancar A Pequena Empresa: Estudo}

De Caso.

Caracteristicamente modelada como uma empresa familiar, a padaria Borks - pães artesanais é um empreendimento idealizado por Fernando Borks Vieira e sua filha Fernanda Bastos Vieira em 2015. Inicialmente estruturada na própria residência dos empreendedores, hoje localiza-se em um edifício comercial na Rua Comendador Rodolfo Gomes, ${ }^{\circ}$ 666, no bairro Menino Deus, em Porto Alegre. Pai e filha têm como intuito oferecer produtos que proporcionem saúde e bem-estar aos seus clientes. Pensando nisso, escolheram por abordar um mercado de nicho dentro de um potencial ramo da economia: o da alimentação saudável. Sua proposta de valor é fornecer alimentos seguros para clientes com restrições alimentares como celíacos, sensíveis ao glúten, alérgicos ao trigo ou glúten, alérgicos à proteína do leite de vaca e intolerantes à lactose, assim como, para clientes adeptos do veganismo. Por isso, dentro de seu planejamento, estruturaram uma cozinha livre de glúten e lactose para produção de seus produtos.

Dentro do seu modelo de negócio, optaram por desenvolver o relacionamento com os clientes por meio de canais de comunicação mais próximos, utilizando as plataformas digitais Instagram, Whatsapp, Facebook e Ifood. Seus produtos são frescos, produzidos no dia, e o empreendimento os divulga diariamente em suas mídias sociais o menu disponível. Também recebe por estes mesmos canais encomendas de seus clientes. De maneira ágil e interativa, a Borks oferece aos seus consumidores um serviço artesanal e, de certo modo, personalizado.

\section{Colocando a mão na massa - o plano de marketing da Borks}

O empreendimento é administrado e diretamente operacionalizado somente pelos dois empresários. Com atividades distintas, Fernando é o responsável pela produção dos pães, aquisição dos insumos, desenvolvimento de novos produtos, toda a atividade operacional dentro da cozinha, enquanto a jovem empresária realiza a gestão de vendas, marketing e controle das finanças da empresa. Há o serviço de tele entrega de seus produtos, que é realizado por meio de empresas parceiras, tais como a plataforma de vendas Ifood.

Em relação aos seus produtos, concomitantemente à venda dos pães sem glúten e sem lactose - oferecidos em dez sabores - a Borks possui uma cartela de produtos em processo de expansão e contínuo desenvolvimento - todos elaborados a partir de receitas próprias do Sr. Fernando. Há biscoitos sortidos, bolos, brownies, pães para hambúrguer, massas para pizzas e 


\section{O Plano De Marketing Como Ferramenta Para Alavancar A Pequena Empresa: Estudo De Caso.}

pizzas prontas, sendo estes dois últimos oferecidos de forma congelada. Os empresários reconhecem a força dos seus produtos, e investem no aprimoramento deles por meio de constantes processos de aperfeiçoamentos nas receitas.

Em entrevista realizada com os empresários, identificou-se que durante o planejamento inicial do negócio foi estruturado um plano de negócios, mas que hoje esse documento já não possui nenhuma conexão com a realidade da empresa. Atualmente também não existe um plano de marketing formal, o que se percebeu foi a implementação de elementos de um plano informal, não escrito, no dia a dia da Borks.

\subsection{Da análise de mercado e suas observações}

Verifica-se que decorrente da natureza do negócio e de seu porte - micro empreendimento, os fatores econômicos e os socioculturais, que o influenciam, atuam de modo positivo no seu sucesso. Apesar de não empregarem formalmente ferramentas como a pesquisa de mercado ou a análise de mercado de maneira planificada, os empresários identificam em seu que, entre os seus consumidores, cerca de $90 \%$ buscam o produto em razão da intolerância ao glúten ou à lactose, ou seja, por uma séria questão médico-alimentar, e que tem como perfil serem entre $80 \%$ a $90 \%$ do sexo feminino, na maioria pessoas mais instruídas, que buscam saber e desenvolver hábitos saudáveis com orientação profissional, representantes em sua das classes B e C.

Pelo controle diário de seu volume de vendas, se depreende que independentemente de a sociedade como um todo encontrar-se sensível aos preços na hora de realizar suas compras, seus consumidores são pessoas que identificam os preços praticados como justos frente às qualidades que os produtos oferecem (preço x massa saudável e sabor agradável). São consumidores que buscam pesquisar preços e opções disponíveis no mercado, e que reconhecem a escassez de opções na região, sentindo-se satisfeitos. Mesmo não utilizando informações de forma planificada, os empresários conhecem o seu mercado. Sabem quem são seus concorrentes diretos - que ofertam pães e outros artigos locais frescos, livre de glúten e de lactose - e que elas contabilizam aproximadamente quatro empreendimentos em Porto Alegre. Auxiliados por esse número, monitoram a média de preços e as características dos 


\section{O Plano De Marketing Como Ferramenta Para Alavancar A Pequena Empresa: Estudo De Caso.}

serviços/produtos disponibilizados pelos concorrentes. Dessa forma, entendem que os seus preços são competitivos frente aos demais, conforme mostra o quadro 1.

Quadro 1 - Média de preços do pão de 500g de menor valor.

\begin{tabular}{|c|c|c|c|c|c|}
\hline \multicolumn{7}{|c|}{ Padarias sem glúten - Porto Alegre } \\
\hline & Borks & $\begin{array}{c}\text { Pólen sem } \\
\text { glúten }\end{array}$ & $\begin{array}{c}\text { Amoa } \\
\text { bakery }\end{array}$ & $\begin{array}{c}\text { Free } \\
\text { bakery }\end{array}$ & $\begin{array}{c}\text { Delivery } \\
\text { sem glúten }\end{array}$ \\
\hline Preço pão 500g & $\mathrm{R} \$ 13,00$ & $\mathrm{R} \$ 12,00$ & $\mathrm{R} \$ 18,00$ & $\mathrm{R} \$ 13,00$ & $\mathrm{R} \$ 12,00$ \\
\hline
\end{tabular}

Fonte: Autor (2019).

A Borks, hoje, não é impactada por fatores políticos, legais e tecnológicos. A possibilidade de novos entrantes é outro fator que não preocupa os sócios uma vez que se trata de um mercado nichado e novo na região. Ainda, dentro da análise de mercado, em continuidade ao ambiente externo, outro fator que se destaca são os fornecedores. Por ser um micro empreendimento, que necessita de muitos insumos orgânicos perecíveis para a produção dos seus produtos, tal ponto exige certo controle e atenção. A falta de um fornecedor que negocie valores nas quantidades necessárias (consideradas pequenas se comparadas a uma padaria convencional) e insumos com características regulares apresenta-se como uma resistência ainda a ser superada.

$\mathrm{Na}$ análise do ambiente interno que circunda o negócio, evidencia-se três fatores que impactam a Borks: o produto, a estrutura física e os canais de comunicação. O primeiro, elemento essencial na estruturação do negócio, possui e representa uma importante força no sucesso do empreendimento. Seus pães, biscoitos e massas são produtos livres de glúten e de lactose, produzidos sem ingredientes à base de soja e sem conservantes, com baixo teor de açúcares refinados e feitos artesanalmente, características que agregam valor e que são valorizadas pelos consumidores. Eles são fabricados a partir de receitas próprias - aspecto que garante exclusividade sobre o principal ativo do negócio - e possibilita a criação de novos produtos baseados numa receita-base. Com essa abordagem a Borks conseguiu formular seu menu de pães, chegando a um total de dez tipos. Em contraponto, em face da não utilização de conservantes, os itens têm prazo de perecibilidade curto, mantendo-se aptos ao consumo por 


\section{O Plano De Marketing Como Ferramenta Para Alavancar A Pequena Empresa: Estudo De Caso.}

até 2 ou 3 dias fora da refrigeração, o que os obriga a serem frescos, produzidos em quantidade limitada para venda diária, e sem possibilidade de formação de estoque de reposição.

O segundo fator é a estrutura do local de produção e vendas. $\mathrm{O}$ empreendimento aluga um espaço em um prédio comercial no bairro Menino Deus, onde situa-se a sua produção e a loja para vendas físicas. A sua localização é um facilitador para o acesso e vendas por tele entregas, já que se trata de uma região central da cidade. O pequeno espaço é dividido em área de vendas e recepção dos clientes e área de produção (a cozinha), as quais são separadas por uma divisória transparente de vidro, permitindo que o cliente observe a organização do ambiente de manipulação e também o processo de produção. A fraqueza presente nesse fator reside na posição da loja, pois trata-se de uma sala de fundos. O cliente deve entrar no prédio para ter acesso à loja e visualizar os produtos. Além disso, apesar do local de produção ser bem organizado e atender as necessidades de espaço do maquinário atual, ele não atenderia a futuras expansões ou a aquisição de máquinas de maior capacidade de produção. Sendo assim, podese considerar tal fato uma barreira ao melhoramento tecnológico e ao aumento na capacidade de produção.

Como último fator interno, estão os canais de comunicação adotados. Influenciada pela era da hiperconectividade, a Borks inseriu a sua promoção de vendas no Instagram, Facebook e Whatsapp, onde divulga seus produtos e o menu diário por fotos e vídeos. Por elas, também recebe encomendas e avaliações. Com essa ação, a Borks é capaz de gerar uma pulverização de seus produtos a custo quase zero - já que o material é produzido pelos empresários. Esse contato digital com os clientes gera um vínculo de identificação com a marca, e consequentemente uma fidelização deles que fica exposta. A rede formada proporciona a criação de um núcleo de clientes promotores, que em razão dos seus comentários positivos e recomendações, formam uma vitrine capaz de influenciar consumidores a fazerem escolhas baseadas nas opiniões.

Dentro da comunicação adotada, outras duas ações também são importantes na análise. A primeira delas é inserção da loja dentro da plataforma do Ifood, empresa que oferece o serviço de delivery de comidas. Ela posicionou a marca dentro de um ambiente em que os consumidores acessam à procura de alimentos e refeições para comprar e surgiu como opção a um público específico: celíacos, intolerantes a lactose e veganos. Analisando a plataforma, na cidade de Porto Alegre há 22 lojas (entre restaurantes, armazéns, padarias, cafés) que oferecem refeições 


\section{O Plano De Marketing Como Ferramenta Para Alavancar A Pequena Empresa: Estudo De Caso.}

sem glúten, porém, ao pesquisar-se padarias que oferecem "pão sem glúten" aparecem somente duas, e no caso de uma pesquisa acerca de "pão sem lactose", o número passa para três encontrando-se a Borks incluída nos números de empresas nas duas pesquisas. A outra ação, por sua vez, é a manutenção de uma loja física para recepção de seus clientes. Essa abordagem fora do ambiente digital abarca os clientes offlines (KOTLER, KARTAJAYA e SETIAWAN, 2017) e possibilita um espaço para que eles possam criar uma relação sensorial com a marca e os produtos. Proporciona uma experiência de compra aos seus consumidores.

Formulado o escopo da análise do mercado em que a Borks está inserida, tanto o ambiente interno quanto o ambiente externo, torna-se viável a formulação da Matriz SWOT (quadro 2) para analisar os pontos fortes e fracos do negócio, assim como, identificar as suas oportunidades e ameaças.

Quadro 2 - Matriz SWOT da Borks.

\begin{tabular}{|c|c|c|}
\hline & Fatores internos (controláveis) & Fatores externos (incontroláveis) \\
\hline $\begin{array}{l}0 \\
0 \\
0 \\
0 \\
0 \\
0 \\
0 \\
0 \\
0 \\
0 \\
0\end{array}$ & $\begin{array}{l}\text { Forças } \\
\text { - Qualidade do produto; } \\
\text { - Boa capacidade de melhoramento e } \\
\text { desenvolvimento de novos } \\
\text { produtos; } \\
\text { - Contato próximo com os } \\
\text { consumidores; } \\
\text { - Localização central. }\end{array}$ & $\begin{array}{l}\text { Oportunidades } \\
\text { - Aumento na demanda por } \\
\text { seus produtos; } \\
\text { - Aumento no número clientes; } \\
\text { - Capacidade de fidelização aos } \\
\text { produtos; } \\
\text { - Poucos concorrentes. }\end{array}$ \\
\hline $\begin{array}{l}0 \\
0 \\
0 \\
0 \\
0 \\
0 \\
0 \\
0 \\
0\end{array}$ & 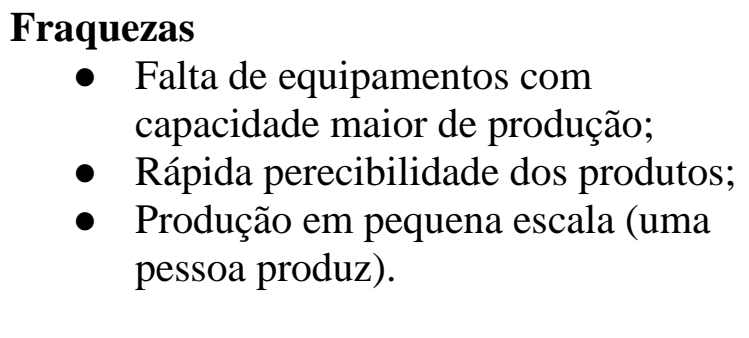 & $\begin{array}{l}\text { Ameaças } \\
\text { - Falta de fornecedores } \\
\text { confiáveis; } \\
\text { - Impacto das intempéries } \\
\text { climáticas na força de vendas; } \\
\text { - Surgimento de novos } \\
\text { empreendimentos. }\end{array}$ \\
\hline
\end{tabular}

Fonte: Autor (2019).

\subsection{Definição dos objetivos e das metas}




\section{O Plano De Marketing Como Ferramenta Para Alavancar A Pequena Empresa: Estudo}

De Caso.

Com as análises realizadas no presente plano de marketing, e a partir da visão e missão (quadro 3) é possível propor à Borks objetivos e metas (SILVA et al., 2006).

Quadro 3 - Visão e Missão da Borks.

\begin{tabular}{|l|l|}
\hline Visão: & $\begin{array}{l}\text { Ser uma padaria referência no fornecimento de alimentos frescos, } \\
\text { saudáveis, sem glúten e sem lactose na região de Porto Alegre, } \\
\text { reconhecida pela qualidade de seus produtos, serviço e atendimento. }\end{array}$ \\
\hline Missão: & $\begin{array}{l}\text { Fornecer alimentos seguros e de qualidade para clientes com restrições } \\
\text { alimentares como celíacos, sensíveis ao glúten, alérgicos ao trigo ou glúten, } \\
\text { alérgicos à proteína do leite de vaca e intolerantes à lactose e veganos. }\end{array}$ \\
\hline
\end{tabular}

Fonte: Autor (2019).

Desta forma, em consonância com a visão e a missão da Borks propõem-se o emprego dos seguintes objetivos e metas abaixo (quadro 4):

Quadro 4 - Objetivos e Metas da Borks.

\begin{tabular}{|l|l|}
\hline \multicolumn{1}{|c|}{ Objetivo de marketing } & \multicolumn{1}{c|}{ Meta de marketing } \\
\hline - Alavancar o número de vendas. & $\begin{array}{l}\text { Aumento de 25\% no número de vendas no } \\
\text { primeiro semestre de 2020. }\end{array}$ \\
\hline - $\begin{array}{l}\text { Fortalecer a marca Borks no mercado de } \\
\text { pães sem glúten e sem lactose. }\end{array}$ & $\begin{array}{l}\text { Aumento de 30\% no número de clientes no } \\
\text { primeiro semestre de 2020. }\end{array}$ \\
\hline $\begin{array}{l}\text { Ser referência em opções de alimentação } \\
\text { sem glúten em Porto Alegre. }\end{array}$ & $\begin{array}{l}\text { Aumento em 15\% na promoção de vendas } \\
\text { para 2020. }\end{array}$ \\
\hline
\end{tabular}

Fonte Autor (2019).

Assim, delineadas finalidades que visam a alavancagem do empreendimento, dentro do plano de marketing passa-se à formulação das estratégias de marketing para alcançá-las.

\subsection{Das estratégias de marketing para alavancar o empreendimento}




\section{O Plano De Marketing Como Ferramenta Para Alavancar A Pequena Empresa: Estudo}

De Caso.

Nessa etapa, é imperativo recordar que as estratégias de marketing, que almejam atingir os propósitos estratégicos anteriormente delineados, devem possuir como seu fundamento a análise de mercado realizada para o empreendimento. Dentro delas são designadas ações que impactam positivamente um ou mais dos objetivos. Seguindo tais ensinamentos, são propostas as seguintes estratégias e ações:

Estratégia no 1 - Realização de Pesquisas de Mercado

Ferramenta importante para a tomada de decisões táticas e embasadas, a aplicação de uma rotina de pesquisas de mercado irá auxiliar a tomada de decisão quanto às ações a serem realizadas. A Borks possui o registro de suas informações internas, mas carece de planificá-las e analisá-las para a gestão do negócio. Por outro ângulo, a aplicação de uma pesquisa junto aos seus clientes e potenciais consumidores mostra-se necessária para identificar realmente como a sua marca é reconhecida. Pode-se afirmar que, hoje, o micro negócio já recebe informações de seus clientes, muito em razão da relação de engajamento que propõe a construir - algumas inclusive resultaram em melhoramentos e desenvolvimentos de novos produtos. Um exemplo, foi o desenvolvimento dos pães com baixo teor de açúcares, ideia decorrente de um cliente. Isto posto, o que se propõe é um aprofundamento nas informações a serem levantadas e no universo a ser pesquisado.

\section{Ações:}

1. Elaborar um questionário para identificar o perfil dos consumidores, as personas do seu negócio;

2. Aplicar pesquisa de satisfação junto aos clientes na loja física e no ambiente virtual;

3. Criar cronograma de aplicação de tais pesquisas e questionários (trimestral, semestral ou anual).

Estratégia 2 - Ampliar a promoção dos produtos

Visando aumentar a participação da marca no cenário local por meio de uma penetração de mercado, sugere-se à Borks investir mais em um marketing direcionado aos seus públicos de interesse locais. Já bem presente nas redes sociais Instagram e Facebook, esta estratégia sugere a atuação no ambiente físico, saindo um pouco do ambiente digital e caminhando em 


\section{O Plano De Marketing Como Ferramenta Para Alavancar A Pequena Empresa: Estudo De Caso.}

direção a um marketing mais individualizado, personalizado e físico para atingir o consumidor que se está offline (KOTLER, KARTAJAYA e SETIAWAN, 2017). A atuação por meio de panfletagens, participações em feiras e eventos locais - especialmente nos voltados à temática na qual a padaria se insere - são formas importantes de gerar contato e engajamento de novos consumidores. Outro modo de abordagem (que já vem sendo trabalhado pela Borks, podendo ser somente reforçado) é a realização de parcerias com outros negócios como restaurantes, armazéns e lojas.

\section{Ações:}

1. Realizar panfletagem em eventos e pontos de concentração de potenciais consumidores, inicialmente nas proximidades da loja e expandindo progressivamente;

2. Participar de feiras e eventos locais/ de bairro com exposição dos seus produtos;

3. Estabelecer parcerias com restaurantes e lojas para divulgação e venda dos produtos - novos pontos de venda;

4. Firmar acordos com restaurantes e cafés de alimentação para utilização dos produtos em seus pratos.

Estratégia 3 - Aumentar a fidelização dos consumidores

Além da busca por novos consumidores é importante o empreendimento manter os clientes que já tem e, portanto, possuem experiência de compra e vínculo com os seus produtos. Nesse sentido, a boa qualidade dos pães, bolos e biscoitos já realiza um trabalho fundamental de manutenção e as ferramentas na internet também produzem um forte engajamento do público com a marca.

As publicações do perfil da Borks na rede social Instagram, que sem a utilização de anúncios patrocinados ou serviços de promoção, alcançam mais de duzentas curtidas em média, com casos de postagens com mais de mil "curtidas", e um significativo número de comentários que indicam a Borks a outros amigos da rede. Sendo assim, percebe-se que existe uma fidelização capaz de tornar o cliente um vendedor da marca (KOTLER, KARTAJAYA e SETIAWAN, 2017) e que também possibilita que a gestão financeira consiga trabalhar com um fluxo de caixa fixo. 


\section{O Plano De Marketing Como Ferramenta Para Alavancar A Pequena Empresa: Estudo}

De Caso.

Exemplos de medidas são a criação de um clube de assinaturas, com periodicidade de entregas, serviços de tele entregas e preços diferenciados para esse tipo de cliente. Outras formas são a criação de um cartão fidelidade, e a promoção de campanhas de brindes (produtos da loja) para os participantes (técnica profundamente adequada para mobilização em nas redes Instagram e Facebook).

\section{Ações:}

1. Criação de um clube de assinaturas com proposta de 3 entregas na semana;

2. Promoção de campanhas de cestas de pães nas redes sociais com a proposta de marcação de amigos da rede nas publicações na periodicidade de 1 por mês;

3. Criação de um cartão fidelidade baseado no número de compras;

\section{Estratégia 4 - Diversificação do público-alvo}

Como forma de ampliar o seu público-alvo, a Borks pode buscar clientes fora do perfil levantado na análise. Não se trata de sair do posicionamento original da marca - pão artesanal fresco, sem glúten e lactose e sem conservantes - mas sim de produzir um produto (um pão) que atenda às necessidades de outros perfis de consumo. Esta abordagem visa comercializar um produto destinado a um consumidor intermediário na cadeia da venda, por exemplo, comercializando massas para pizzas ou pães de hambúrgueres.

\section{Ações:}

1. Oferta dos produtos da marca para clientes comerciais como restaurantes, bares e até padarias tradicionais (que não ofertam produtos para pessoas com restrições alimentares);

2. Apresentação do produto em eventos e feiras destinados aos empresários de bares e restaurantes;

3. Desenvolvimento de um produto com capacidade de adaptabilidade ao negócio do cliente, tal como um pão específico para a elaboração de cachorro-quente.

Após delineadas as estratégias de marketing para a Borks, com suas ações definidas, cabe aos dois empresários definirem prazos e responsáveis pela execução e acompanhamento delas. A implementação, o controle e a reavaliação das estratégias a partir de fatores de métrica 


\section{O Plano De Marketing Como Ferramenta Para Alavancar A Pequena Empresa: Estudo}

De Caso.

definidos (ex. comparativo da lucratividade ou do volume de vendas a cada ação) e do plano de marketing como um todo deve ser realizado periodicamente.

\section{Considerações finais}

Por meio do estudo de caso da padaria Borks, constatou-se que a realidade brasileira se mostra como um universo muito promissor ao empreendedorismo, pois é um mercado que necessita de empreendedores e que apresenta um grande número de potenciais consumidores em diversos nichos, singularmente no de alimentação saudável. Ainda, a partir do fato de que no Brasil a falta de planejamento é um dos principais fatores responsáveis pela elevada taxa de mortalidade das pequenas e micro empresas, observou-se que é vital que elas tenham acesso e façam uso de ferramentas de gestão de negócios, mais especificamente: um plano de marketing. Não importando o seu porte, o plano de marketing é uma ferramenta contributiva ao sucesso e longevidade da empresa.

Tendo-se como base a entrevista realizada com os empresários, a elaboração da análise de mercado do empreendimento e a do estudo da relação entre negócio e cliente, foi constatado que o empreendimento possui um produto muito bem avaliado pelos seus consumidores. Entretanto, baseando-se no referido diagnóstico, notou-se que havia a possibilidade de lucros maiores e de atingir-se resultados mais significativos para o negócio caso fosse utilizada uma estratégia de marketing bem definida, algo ainda não adotado pela empresa.

Fundamentando-se em elementos básicos de um plano de marketing, como a análise de ambiente, a formulação de objetivos e metas e a ampliação do mix de marketing, delineou-se que é possível que um pequeno empreendimento de bairro atinja objetivos de distintas naturezas e, assim, em pouco tempo consiga alavancar suas vendas e/ ou ampliar seu público consumidor. Por fim, de modo a proporcionar oportunidades de crescimento à Borks, buscou-se apresentar viáveis e personalizadas estratégias de marketing aos empreendedores Fernando e Fernanda, com a formulação de ações táticas e gerenciáveis periodicamente.

Almeja-se que este estudo valha como base acadêmica para futuros pesquisadores desta matéria, assim com, assista como instrumento no processo de desenvolvimento de comportamentos empreendedores, mais especificamente, dentro do universo da aprendizagem empreendedora. Espera-se que plano de marketing proposto à pequena padaria artesanal Borks 
O Plano De Marketing Como Ferramenta Para Alavancar A Pequena Empresa: Estudo De Caso.

sirva como uma ferramenta de facilitação e planificação das estratégias para o alcance dos objetivos do negócio, garantindo que resultados positivos sejam gerados, mensurados e mantidos. E, sendo assim, uma iniciativa de extrema relevância para nortear as ações deste "pequeno grande empreendimento".

\section{Referências bibliográficas}

ANDERSON, Chris. A Cauda Longa. Rio de Janeiro: Elsevier, 2006.

BEUREN, Ilse Maria. (Org.). Como elaborar trabalhos monográficos em contabilidade: teoria e prática. São Paulo: Atlas, 2010.

BORKS PÃES ARTESANAIS (Brasil). Instagram: paesborks. Disponível em: <https://www.instagram.com/paesborks/?hl=pt-br>. Acesso em: 01 nov. 2019.

BORKS PÃES ARTESANAIS. Facebook: Borks Pães Artesanais. Disponível em: <https://www.facebook.com/paesborks/>. Acesso em: 01 nov. 2019.

BORKS PÃES ARTESANAIS. Ifood: Borks Pães Artesanais. Disponível em: $<$ https://www.ifood.com.br/delivery/porto-alegre-rs/borks-paes-artesanais-meninodeus/17ecbbba-0d4e-4f37-b4ce-4d77cb86a814>. Acesso em: 01 nov. 2019.

CASTELLS, Manuel. A galáxia da internet: reflexões sobre a internet, os negócios e a sociedade. Rio de Janeiro: Zahar, 2003.

COBRA, Marcos. Administração de marketing no Brasil. Rio de Janeiro: Elsevier, 2009.

DOLABELA, Fernando. Oficina do empreendedor. São Paulo: Cultura Editores Associados, 1999.

DORNELAS, José. Empreendedorismo: transformando ideias em negócio. 6. ed. São Paulo: Empreende/Atlas, 2016.

DORNELAS, José. Empreendedorismo: transformando ideias em negócios. 4. ed. Rio de Janeiro: Elsevier, 2012.

FENACELBRA. Disponível em: <http://www.fenacelbra.com.br/fenacelbra/fenacelbra-lancaa-campanha-reconhecer/>. Acesso em: 03 nov. 2019.

FONSECA, João José Saraiva. Metodologia da pesquisa científica. Fortaleza: UECE, 2002. Disponível em: <http://www.ia.ufrrj.br/ppgea/conteudo/conteudo-2012-1/

1SF/Sandra/apostilaMetodologia.pdf >. Acesso em: 05 nov. 2019. 
O Plano De Marketing Como Ferramenta Para Alavancar A Pequena Empresa: Estudo De Caso.

GERHARDT, Tatiana Engel; SILVEIRA, Denise Tolfo (Org.). Métodos de pesquisa. Porto Alegre: Editora da UFRGS, 2009.

GOMES, Isabela Motta. Como elaborar um plano de marketing. 3.ed. Belo Horizonte: SEBRAE/MG, 2013.

KOTLER, Philip. Administração De Marketing: Análise, Planejamento, Implementação e Controle. $6^{\text {a }}$ ed. São Paulo: Atlas, 2001.

KOTLER, Philip; KELLER, Kevin Lane. Administração de marketing. 14. ed. São Paulo: Pearson Education do Brasil, 2012.

KOTLER, Philip; ARMSTRONG, Gary. Princípios de marketing. 9. ed. São Paulo: Pretince Hall, 2003.

KOTLER, Philip; KARTAJAYA, Hermawan; SETIAWAN, Iwan. Marketing 4.0 do tradicional ao digital. Rio de Janeiro: Sextante, 2017.

POLIZEI, Eder. Plano de marketing. Revista da Faculdade de Administração e Economia, v. 2, n. 2, p. 184-186, 2010.

PINHEIRO, Duda; GULLO, José. Comunicação Integrada de Marketing: gestão dos elementos de comunicação. Suporte às estratégias de marketing e de negócios da empresa: 4. ed. Atlas: São Paulo, 2013.

SEBRAE. Alimentação saudável cria ótimas oportunidades de negócio. Disponível em: <https://www.sebrae.com.br/sites/PortalSebrae/artigos/artigoshome/ segmento-dealimentacao-saudavel-apresenta-oportunidades-denegocio,f48da82a39bbe410VgnVCM1000003b74010aRCRD>. Acesso em: 22 out. 2019.

SEBRAE. Estudo de Mercado: pequenos negócios em números. Disponível em: <http://www.sebrae.com.br/sites/PortalSebrae/ufs/sp/sebraeaz/pequenos-negocios-emnumeros, 12e8794363447510VgnVCM1000004c00210aRCRD>. Acesso em: 22 out. 2019.

SEBRAE. Planejamento Estratégico: use a matriz F.O.F.A. para corrigir deficiências e melhorar a empresa. Disponível em: <https://www.sebrae.com.br/sites/ PortalSebrae/artigos/use-a-matriz-fofa-para-corrigir-deficiencias-e-melhorar-aempresa,9cd2798be83ea410VgnVCM2000003c74010aRCRD>. Acesso em: 05 nov. 2019.

SILVA, Helton H.; TENCA, Evandro C.; SCHENINI, Paulo Henrique; FERNANDES, Sandra. Planejamento estratégico de marketing. 3. ed. Rio de Janeiro: Editora FGV, 2006.

STRINGHINI, João. Dicionário Stringhini: dicionário de termos e expressões em marketing. Porto Alegre: Sul Editores, 2007. 
O Plano De Marketing Como Ferramenta Para Alavancar A Pequena Empresa: Estudo De Caso.

YIN, Robert K. Estudo de caso: planejamento e métodos. 2. ed. Porto Alegre: Bookman, 2001.

ZAMPIER, Marcia Aparecida; TAKAHASHI, Adriana Roseli Wünsch. Competências empreendedoras e processos de aprendizagem empreendedora: modelo conceitual de pesquisa. Cadernos Ebape. BR, v. 9, p. 564-585, 2011. 